\title{
Balancing biosynthesis and bioenergetics: metabolic programs in oncogenesis
}

\author{
Jennifer F Barger and David R Plas \\ Department of Cancer and Cell Biology, University of Cincinnati, Cincinnati, Ohio 45267, USA \\ (Correspondence should be addressed to D R Plas; Email: plasd@uc.edu)
}

\begin{abstract}
Cancer biologists' search for new chemotherapy targets is reinvigorating the study of how cancer cell metabolism determines both oncogenic potential and chemotherapeutic responses. Oncogenic metabolic programs support the bioenergetics associated with resistance to programed cell death and provide biosynthetic building blocks for cell growth and mitogenesis. Both signal transduction pathway activation and direct mutations in key metabolic enzymes can activate the metabolic programs that support cancer cell growth. Cancer-associated metabolic programs include glycolysis, glutamine oxidation, and fatty acid metabolism. Recent observations are revealing the regulatory mechanisms that activate cancer-associated metabolism, and the competitive advantages provided to transformed cells by their metabolic programs. In this study, we review recent results illustrating the mechanisms and functional impact of each of these oncogenic metabolic programs in cancer cell growth and survival.
\end{abstract}

Endocrine-Related Cancer (2010) 17 R287-R304

\section{Introduction}

Cancer-associated functional changes have been conceptualized as the hallmarks of transformed cells, including unrestrained cell growth, autonomous mitogenesis, and resistance to apoptosis. Perhaps to satisfy the metabolic demands of these processes, cell transformation is also frequently associated with elevated cellular metabolism. Recently, newly uncovered links between oncogene-induced signal transduction networks and metabolic enzymes have rekindled interest in targeting cancer cell metabolism with chemotherapeutics. These advances raise fundamental questions in carcinogenesis: what determines the metabolic portfolio of cell metabolism in cancer cells? What is the functional benefit of specific metabolic programs to cancer cell growth and survival? In this review, we aim to describe metabolic alterations that are associated with cell transformation (Fig. 1), the mechanisms linking metabolism to oncogenes, and the functional impact of altered metabolism for cancer growth and chemotherapy.

\section{Glycolysis: the metabolic program for growth and survival Glycolysis in cancer cells}

Glycolysis is the metabolic program of choice for cells that are actively engaged in cell growth and mitogenesis. A number of models have been proposed to explain the preference for glycolytic metabolism in transformed cells: i) bioenergetic demand due to mitochondrial defect - cancer cells have no other choice, because mitochondrial oxidative phosphorylation has been compromised by cancer-causing mutations; ii) biosynthesis - glycolytic metabolism generates biochemical intermediates that are useful for the synthesis of macromolecules for cell proliferation, such as fatty acids and nucleotides; iii) temporal programing - metabolic programs are utilized by cells according to patterns established by oscillating control mechanisms in the cell, such as cell cycle. Recent advances supporting each of these perspectives and their implications for cancer therapy are discussed below. 


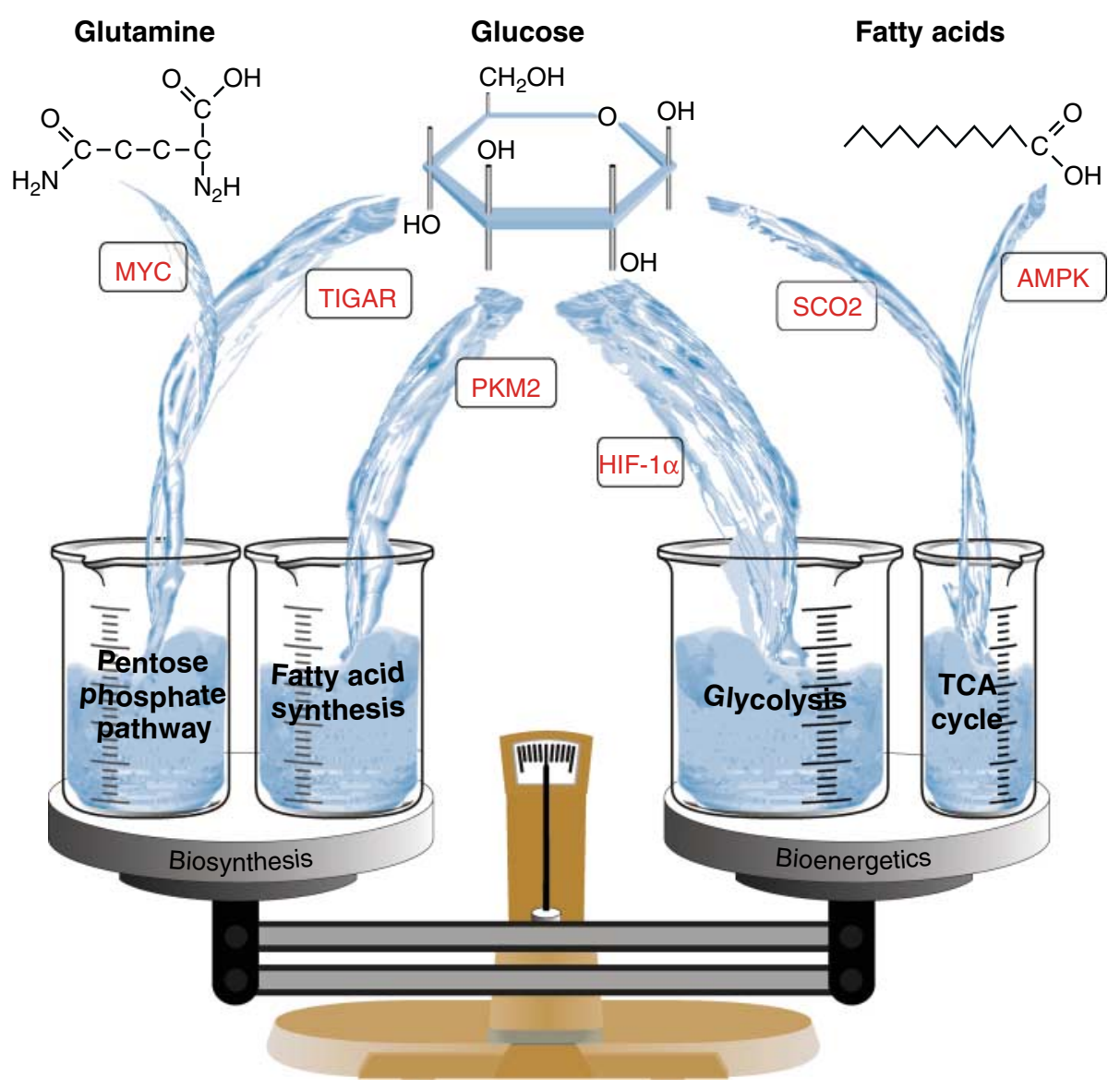

Figure 1 The bioenergetic and biosynthetic requirements of cancer cells are balanced by regulating the flux of pathways that metabolize glucose, glutamine, or fatty acids. Key regulatory mechanisms that determine the flux from each carbon source into the pathways are highlighted. The model shows HIF-1 $\alpha$ and AMPK driving increased bioenergetic input derived from glucose and fatty acids. PKM2, TIGAR, or c-Myc can promote the flux of glucose or glutamine into biosynthetic pathways. SCO2 promotes glucose oxidation via the TCA cycle.

\section{Bioenergetic demand}

In his pioneering work describing decreased oxidative metabolism coupled with increased glycolysis in cancerous tissues, Warburg et al. (1931) observed that the acquisition of glycolytic metabolism is irreversible, as transformed cells rarely revert to an oxidative form of metabolism. This is in contrast to embryonic tissues, which exhibit high rates of glycolysis but eventually switch to oxidative metabolism as proliferation ceases and cells differentiate. One possible explanation for the inability of cancer cells to engage oxidative metabolism is the acquisition of mutations in key enzymes, in effect delivering a 'metabolic injury' that irrevocably alters metabolic flux. As genomic data from cancer cells accumulate, new oncogenic mutations in metabolic enzymes are emerging, thus demonstrating the critical impact of metabolic pathways in maintaining cellular homeostasis.
Mutations that disrupt mitochondrial respiration can occur in genes encoded by nuclear or mitochondrial DNA. In mitochondrial DNA, deletions and mutations in protein coding regions have been associated with multiple cancers, including breast and prostate cancer (Wallace 2005). Sporadic and familial mutations inactivating the nuclear-encoded subunits of the succinate dehydrogenase (SDH) complex trigger the development of pheochromocytoma and paraganglioma (Lehtonen et al. 2004). Similarly, lossof-function mutations in fumarate hydratase $(\mathrm{FH})$ can contribute to leiomyomas and renal cell carcinomas (Sudarshan et al. 2009). Mutations in the SDHB, SDHC, and SDHD subunits of SDH impair the TCA cycle, resulting in reduced charging of the electron transport chain, decreased ATP production, the generation of reactive oxygen species (ROS), and elevated succinate levels. Recently, mutations in $\mathrm{Sdh} 5$, a protein 
that associates with the SDH complex and may mediate incorporation of FAD, have been identified in familial paraganglioma (Hao et al. 2009).

It stands to reason that impaired oxidative phosphorylation in the mitochondria would lead to compensatory increases in glycolysis, but it is critical to identify the mechanisms that mediate increased glycolysis under these circumstances. One possible explanation is that rising AMP levels in cells trigger allosteric activation of glycolytic enzymes, such as phosphofructokinase 1 (PFK1). However, the carcinogenic effect of an AMP-dependent activation of glycolysis is likely to be counteracted by the tumor suppressor effects of the AMP-activated protein kinase (AMPK). AMPK can phosphorylate and activate p53 tumor suppressor activity and directly inactivate the pro-growth kinase complex known as mammalian target of rapamycin complex 1 (mTORC1; Jones et al. 2005). Active p53 facilitates glucose oxidation via the TCA cycle by driving the production of cytochrome $c$ oxidase assembly factor $\mathrm{SCO} 2$ (Matoba et al. 2006). Thus, a rise in AMP as a consequence of impaired TCA cycle function is not likely to contribute to oncogenic metabolism.

An alternative mechanism for activation of glycolysis in SDH mutant cells is based on the integration of key metabolites in the regulation of the hypoxia inducible factor- $1 \alpha$ (HIF- $1 \alpha$ ). When HIF- $1 \alpha$ pairs with the HIF-1 $\beta$-binding partner, it forms a transcription factor that binds and activates the promoters of multiple glycolytic genes (Wang et al. 1995). In resting cells, proline hydroxylase enzymes (PHDs) hydroxylate two prolines in HIF-1 $\alpha$, targeting the protein for degradation by a Von Hippel-Lindau (VHL)-linked ubiquitin ligase complex (Bruick \& McKnight 2001, Epstein et al. 2001, Ivan et al. 2002). PHD enzymes consume oxygen and $\alpha$-ketoglutarate (also known as 2-oxoglutarate) and generate succinate in the process of hydroxylating proline residues in HIF-1 $\alpha$ (Fig. 2). Decreased oxygen abundance is sufficient to inhibit HIF-1 $\alpha$ proline hydroxylation, preventing HIF- $1 \alpha$ degradation by the VHL ubiquitin ligase complex, and thereby triggering the accumulation of HIF- $1 \alpha / \mathrm{HIF}-1 \beta$ transcriptional complexes on the promoters of glycolytic genes.

The exquisite sensitivity to oxygen abundance suggests that PHD enzymes may also be sensitive to the concentrations of the other metabolites involved in the reaction, namely $\alpha$-ketoglutarate and succinate. An important advance was the demonstration that SDHdeficient cells accumulate increased succinate, impairing PHD activity and triggering HIF- $1 \alpha$ accumulation (Selak et al. 2005). This observation was supported by
A

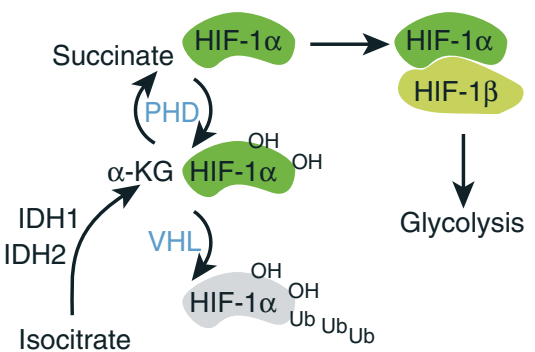

B

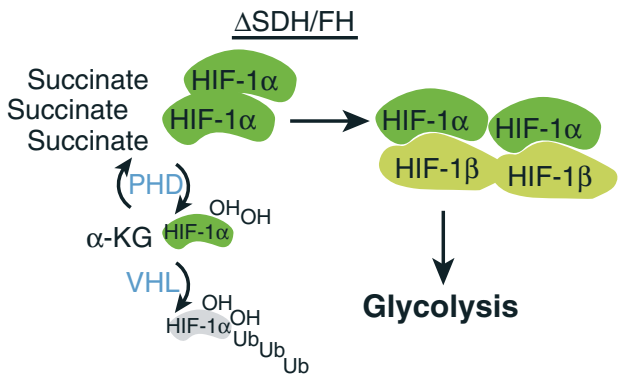

C

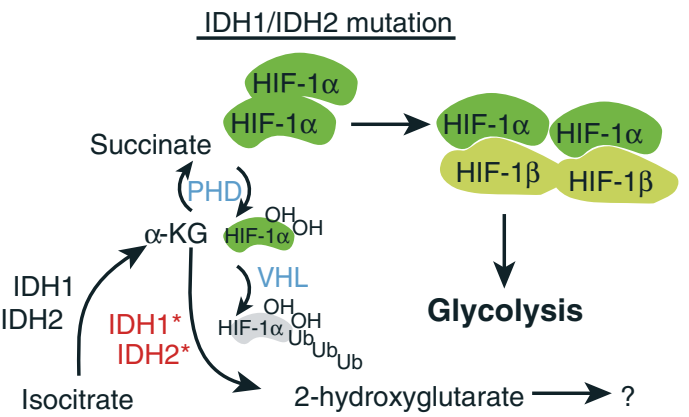

Figure 2 Regulation of HIF-1 $\alpha$ in response to mutations in metabolic enzymes. (A) HIF- $1 \alpha$ is hydroxylated at proline residues by the PHD enzymes, a reaction that requires $\alpha$-ketoglutarate and produces succinate. Hydroxylated $\mathrm{HIF}-1 \alpha$ is ubiquitinated by a VHL-containing ubiquitin ligase. (B) Mutations in SDH or FH enzymes trigger accumulation of succinate, impairing HIF- $1 \alpha$ hydroxylations. Increased HIF-1 $\alpha$ drives increased glycolysis. (C) Mutant forms of IDH1 or IDH2 (marked with an asterisk) may reduce the availability of $\alpha$-ketoglutarate, restricting HIF- $1 \alpha$ hydroxylation and activating glycolysis. An alternative model proposes that mutated IDH enzymes acquire a novel activity, producing increased 2-hydroxyglutarate. The effects of 2-hydroxyglutarate on the signal transduction and metabolism of transformed cells are not yet well described.

measurement of increased succinate and HIF- $1 \alpha$ levels in primary paraganglioma tumor samples (Pollard et al. 2005). Familial cancer-predisposing mutations in SDH and FH have established the principle that mitochondrial injury can be a primary event in oncogenesis, but the overall impact of mitochondrial function in the understanding of carcinogenesis has been diminished because of the relatively small proportion of cancers that are affected by these mutations. 
With greater frequency than the SDH/FH mutations, mutations in isocitrate dehydrogenase 1 (IDH1) and the related enzyme IDH2 have been detected in glioblastoma and acute myeloid leukemia (AML; Parsons et al. 2008, Mardis et al. 2009). Genome sequencing of glioblastoma and AML has identified mutant forms of IDH1 or IDH2 in $\sim 33 \%$ of cytogenetically normal leukemias (Marcucci et al. 2010). In one model, it is proposed that these mutations cause loss-of-function in the IDH1/IDH2 enzymes, decreasing the availability of $\alpha$-ketoglutarate, and thus depriving the cells of a key substrate needed to carry out PHD-dependent HIF-1 $\alpha$ hydroxylation (Fig. 2; Zhao et al. 2009). However, it has also been reported that glioblastomas and AML cells do not have decreased levels of $\alpha$-ketoglutarate, and instead that IDH mutant enzymes have a gainof-function in which they produce a new metabolic product: 2-hydroxyglutarate (Dang et al. 2009, Gross et al. 2010, Ward et al. 2010). Key experiments to determine the activity of PHD enzymes in IDH mutant tumors are required to determine whether the lossof-function or gain-of-function mechanisms best explains the oncogenic effects of IDH mutations.

\section{Biosynthetic contributions}

Many of the biosynthetic pathways in the cell originate with the conversion of glycolytic intermediates into biosynthetic precursors. Although glycolysis generates a low yield of ATP relative to oxidative forms of metabolism, glycolysis can provide a rich source of biosynthetic intermediates that can be used for amino acid production, nucleic acid production, and glycerol synthesis. Several biosynthetic pathways have demonstrated critical roles in cancer.

A key biosynthetic pathway fed by the first steps of glycolysis is the pentose phosphate pathway (PPP). In the PPP, 6-phosphoglucose is diverted from the glycolytic pathway to generate pentose sugars and $\mathrm{NADPH}$, an important reducing equivalent in the cell. Enhanced activation of the PPP has a number of prooncogenic effects. In xenograft models of breast cancer, tropism for brain metastasis was shown to correlate with increased expression of PPP enzymes and the production of NADPH (Chen et al. 2007a). Similarly, three-dimensional culture models of breast cancer oncogenesis have reported increased production of NADPH by the PPP as an important metabolic pathway for maintaining the survival of basement membrane-detached cells that accumulate in luminal structures (Schafer et al. 2009).

NADPH production benefits cancer cells via multiple mechanisms: facilitating biosynthetic reactions, detoxifying ROS, and initiating signal transduction that controls caspase 2. The key NADPH-dependent biosynthetic reactions are fatty acid synthesis, cholesterol synthesis, and nucleotide biosynthesis. In hormone-responsive tumors, fatty acid synthesis is increased by hormone receptor signaling, and inhibitors of fatty acid synthesis are known to be cytotoxic for cancer cells in vivo and in vitro (Kuhajda 2000, Guo et al. 2009). Increased fatty acid synthesis has been linked to poor prognosis in breast cancer and prostate cancer (Kuhajda et al. 1989, Shurbaji et al. 1996). It is thought that increased fatty acid synthesis is important for lipid modification of signal transduction subunits and the synthesis of new membrane in dividing cells (see below).

NADPH production is also critical for detoxifying ROS. Although increased ROS has been noted in many types of cancers (Toyokuni et al. 1995), it is also clear that transformed cells must balance ROS levels to maintain cell viability and optimal proliferative capacity. Indeed, overproduction of ROS on treatment with chemotherapeutics, such as 5-fluorouracil and doxorubicin, is thought to be an important mechanism for inducing cell death (Hwang et al. 2001). Conversely, reduction of ROS in cancer cells promotes apoptosis resistance via two mechanisms. In one mechanism, suppression of ROS promotes cell survival by increasing the capacity of cells to sustain metabolism through increased fatty acid oxidation (Schafer et al. 2009). Fatty acid oxidation can sustain cancer cell viability when other metabolic pathways such as glycolysis are unavailable (Buzzai et al. 2005). Furthermore, in some cell types the pro-apoptotic activity of cytochrome $c$ can be regulated by the reducing potential of the cell (Vaughn \& Deshmukh 2008). ROS-oxidized cytochrome $c$ is more potent in inducing caspase 9 activation than the reduced form of cytochrome $c$, after mitochondrial permeabilization. Prevention of cytochrome $c$ oxidation was shown to be dependent on the production of anti-oxidants by the PPP (Vaughn \& Deshmukh 2008).

There is evidence that the PPP also contributes to direct regulation of pro-apoptotic proteins through NADPH-induced phosphorylation control of caspase 2. Caspase 2 is a potentially useful chemotherapeutic target because of its ability to mediate cell death via a mechanism that is independent of p53 and insensitive to overexpression of pro-survival $\mathrm{Bcl}-2$ family proteins (Sidi et al. 2008). High levels of NADPH induce the activity of the calcium/calmodulin-dependent protein kinase II (CaM kinase II), which in turn phosphorylates caspase 2 at S315, preventing caspase 2 activation by providing a phospho-serine-binding site 
for 14-3-3 family proteins (Nutt et al. 2005, 2009). However, there is a need for more extensive analysis of caspase 2 regulation in the context of transformed cancer cells before these mechanisms can be fully explored for chemotherapeutic targeting. Importantly, caspase 2 is also suggested to be a critical regulator of cell cycle checkpoints in response to irradiation, indicating that metabolic regulation of caspase 2 should also be considered for combination with therapeutics that disrupt cell cycle progression and DNA repair (Kitevska et al. 2009).

One mechanism controlling flux of glycolytic intermediates to the PPP versus glycolysis is regulated in part through the effects of p53 and its transcriptional target TP53-induced glycolysis and apoptosis regulator (TIGAR). The TIGAR protein contains a domain that is homologous to the phosphatase domain of 6-phosphofructo-2-kinase/fructose-2,6 bisphosphatase (PFK2). Increased expression of TIGAR suppresses the flux of glucose to downstream elements of the glycolytic pathway, thereby increasing the abundance of glucose-6-phosphate, which then enters the PPP (Bensaad et al. 2006). Increased TIGAR correlated with protection from apoptosis induced by doxorubicin (adriamycin) and other apoptotic stimuli associated with the generation of ROS (Bensaad et al. 2006). Interestingly, TIGAR can also regulate ROS levels in cells through effects on autophagy, a process that allows cells to consume intracellular macromolecules under conditions of nutrient deprivation (Bensaad et al. 2009). The ability of TIGAR to regulate the switch between bioenergetic production through glycolysis and biosynthetic production suggests that the expression of this molecule in various cancer types may be key for determining the optimal metabolic pathways to be targeted in chemotherapy.

Beyond the regulation of PPP versus glycolysis in the first few steps of glycolysis, the utilization of glucosederived carbons for glycolysis or biosynthesis is also affected by the differential expression of pyruvate kinase (PK) isoforms. PK catalyzes the penultimate step of glycolysis, converting phosphoenolpyruvate to pyruvate and generating ATP as a result. Alternative mRNA splicing triggers the production of two isoforms of PK in most tissues: PKM1 and PKM2. Compared to PKM2, PKM1 can form a tetrameric structure that has a higher affinity for its substrate (phosphoenolpyruvate) and is associated with increased cellular ATP:ADP ratios (Mazurek et al. 2005). PKM2 forms a dimeric structure, with decreased affinity for phosphoenolpyruvate and can be allosterically regulated by binding to tyrosine phosphorylated peptides and by 2,6-bisphosphofructose (Christofk et al. 2008b).
These characteristics might suggest that PKM1 would be associated with oncogenesis. However, PKM2 expression is tightly associated with cell transformation.

By preferentially expressing PKM2 instead of PKM1, cancer cells sacrifice the potential to generate ATP to increase the abundance of upstream metabolites in the glycolytic pathway. As described above, the diversion of glucose 6-phosphate into the PPP can promote the synthesis of fatty acids and cholesterol through the production of NADPH. However, decreased PK activity also increases the abundance of glyceraldehyde-3-phosphate and 3-phosphoglycerate, which can contribute to the synthesis of nucleic acids and amino acids respectively. Thus, the expression of PKM2 suggests that a major destination of carbon derived from glucose in cancer cells is biosynthesis of macromolecular structures.

The importance of PKM2 expression during cellular transformation is demonstrated by substituting PKM1 expression for PKM2 in cancer cell lines (Christofk et al. 2008a). In vitro, there is no difference in the growth rate of cancer cells with PKM1 expression. However, xenograft experiments reveal a striking decline in the growth rate of PKM1-expressing tumor cells. This result indicates that in vivo conditions require greater coordination of metabolic pathways to support biosynthesis, and that PKM2 expression is a critical enzyme that supports this process.

Expression of PKM1 versus PKM2 can differ by tissue type, but PKM2 expression is correlated with cell cycle progression and cellular transformation (Christofk et al. 2008a, Clower et al. 2010). The splicing factors known as polypyrimidine tract-binding protein (PTB - also known as PTBP1 or heterogeneous nuclear ribonucleoprotein A1 (hnRNP1)), hnRNPA1 and hnRNPA2 mediate the switch from expression of PKM1 to PKM2 (Clower et al. 2010, David et al. 2010). Increased abundance of PTB, hnRNP1, and hnRNP2 is increased on expression of the proglycolytic transcription factor c-Myc (David et al. 2010). Increased c-Myc correlated with PKM2 expression in gliomas, indicating that c-Myc activity may be important for reprograming cellular metabolism to support oncogenesis in this tumor type.

PTB and hnRNP proteins regulate PKM splicing by binding to sites proximal to PKM1-specific Exon 9, inhibiting Exon 9 splicing and resulting in splicing of the PKM2-specific Exon 10. Knockdown experiments reveal that hnRNPA1 and hnRNPA2 function redundantly to inhibit PKM1 production, while PTB knockdown alone was sufficient to restore expression of PKM1 (Clower et al. 2010, David et al. 2010). Unexpectedly, increased PKM1 expression on 
knockdown of PTB or hnRNPs suppressed lactate production, despite the increased catalytic activity of PKM1 to produce pyruvate, relative to PKM2 (Clower et al. 2010). This may suggest that the PKM1/PKM2 paralogs affect the destination of glucose-derived carbon (TCA cycle versus lactate), or that the PTB and hnRNP proteins affect multiple enzymes in the glycolytic pathway.

Increased PTB expression has been noted in some cancers, although expression levels do not in all cases correlate with metastatic potential or stage of malignancy (Jin et al. 2000, He et al. 2004, Wang et al. 2008). Interestingly, knockdown of PTB in cancer cell lines suppresses cell proliferation in semisolid media. Owing to the likelihood that alterations in splicing factors affect multiple aspects of cell function, it will be necessary to investigate whether the primary effects of suppressing PTB are mediated by alterations in PKM isoforms or whether other pathways are also critical.

\section{Temporal programing}

Although it is clear that regulation of metabolic pathways can solve bioenergetic and biosynthetic problems for cancer cells, a new perspective on the functional benefits of metabolic pathways has emerged from studies of the temporal regulation of metabolism. Beginning in yeast grown in continuous concentrations of nutrients, Tu et al. (2005) observed oscillations in the oxygen consumption of yeast, which correlated with entry of cells into $S$ phase of the cell cycle. In the $G_{1}$ phase, oxidative metabolism is engaged, while ribosome and protein synthesis generate intense demand for ATP. During cell replication, cells switch to glycolytic metabolism, thereby reducing the risk of genomic damage due to ROS generated by oxidative metabolism (Chen et al. 2007b). These observations establish the concept that cells coordinate their metabolic program in synchrony with major cellular functions, such as cell cycle progression or ribosome biogenesis.

The importance of temporal coordination in setting metabolic programs in cancer cells is suggested by the observation of decreased expression of the period (PERl) gene in human samples of non-small cell lung carcinoma and breast cancer (Gery et al. 2006, 2007a). The period genes (Per1, Per2, and Per3) are expressed in most mammalian tissues to regulate the metabolic machinery in anticipation of events such as nutrient influx or increased energetic demand. Period proteins associate with cryptochrome (CRY) proteins to regulate the activity of the central circadian rhythm transcription factors BMAL1 and Clock. Circadian rhythm is established through a negative feedback loop in which period:cryptochrome complexes inhibit BMAL1:Clock, until the period:cryptochrome complexes are dissociated or degraded. The subsequent increases in BMAL1:Clock transcriptional activity drive expression of period and cryptochrome, which accumulate until BMAL1:Clock activity is restrained (Fig. 3). The BMAL1:Clock transcription factor regulates the expression of enzyme components of multiple metabolic pathways, including glycolysis. Please see Takahashi et al. (2008) for a recent review.

The expression levels of period proteins cycle in response to changes in the upstream central circadian rhythm genes BMAL1 and Clock, and also to various inputs ranging from metabolism to signal transduction (Sahar \& Sassone-Corsi 2009). Transcriptional targets controlled by the circadian clock include both cell cycle regulators and key metabolic enzymes such as PK, suggesting that the coordination of the replicative cell cycle and the metabolic cycle could be mediated by the period genes (Lamia et al. 2008). Inactivation of the related gene Per2 in mice triggers hyperplasia of the salivary glands, epidermal teratomas, and lymphoma. (Fu et al. 2002). In breast cancer, deregulated expression of Per2 has been tied to estrogen receptor activation (Gery et al. 2007b). A modest increase in breast cancer incidence has been noted in women whose circadian rhythms are altered due to nighttime working hours (Schernhammer et al. 2006).

Recently, AMPK, a major effector of the tumor suppressor activity of LKB1, was shown to regulate circadian rhythms by phosphorylating and destabilizing the circadian transcription factor CRY1 (Lamia et al. 2009). AMPK suppresses oncogenic signal transduction by opposing the activation of mTORC1,

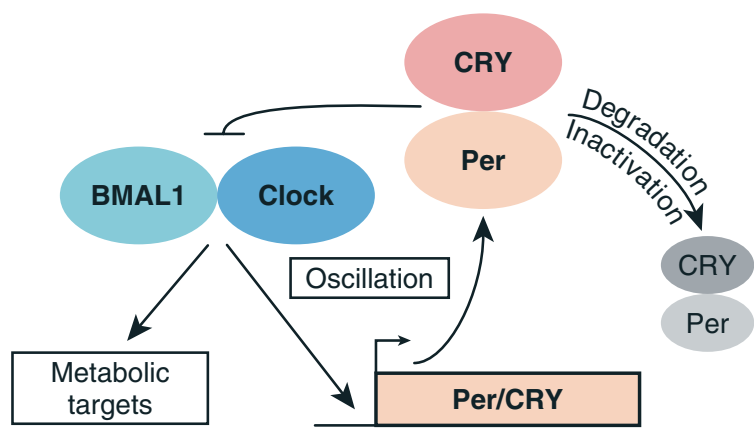

Figure 3 The circadian clock in cancer. BMAL1:Clock proteins regulate transcription of their inhibitors, period, and cryptochrome genes. Degradation of period and cryptochrome proteins activates BMAL1:Clock in the regulation of a large number of transcriptional targets, including genes that regulate glycolysis and other metabolic pathways. 
a critical kinase that controls cell growth, survival, and metabolism. Cry $1^{-1-}$ mice have reduced tumorigenesis in a $553^{-1-}$ background, suggesting that an additional mechanism for AMPK tumor suppressor activity could be mediated by phosphorylation and destabilization of CRY1 (Ozturk et al. 2009). Further study will be needed to determine whether the seemingly contradictory effects in oncogenesis of $C R Y 1^{-1-}$ (decreased cancer) and Per2 ${ }^{-1-}$ (cancer susceptibility) are reflected in opposing effects on cellular metabolism.

If temporal programing is a key determinant of the activation of glycolysis, then an important question is whether cancer therapy can be timed to maximize chemotherapeutic response by anticipating alterations in metabolic pathways. Although the mechanisms are not fully elucidated, there are a number of reports of increased chemotherapeutic responses when administration of drugs is timed according to diurnal cycle (Haus et al. 1972, Boughattas et al. 1989, Takahashi et al. 2008). In mice, B-cell cytotoxicity in response to cyclophosphamide varies according to the circadian clock, an effect that can be genetically replicated by increased cytotoxicity in Clock mutant mice (Gorbacheva et al. 2005). Conversely, CRY1-deficient B cells (which have increased BMAL1:Clock activity) are resistant to the cytotoxic effects of cyclophosphamide. Importantly, the differential responses of Clock- or CRYI-deficient mice were not linked to alterations in cyclophosphamide pharmacokinetics. Considering these results in the context of increased lymphoma in $\mathrm{Per} 2^{-1-}$ mice, it will be interesting to learn in future studies whether the effects of circadian regulation are related to cell-intrinsic effects on metabolism and apoptosis.

What do we learn from the various roles of glycolysis in carcinogenesis? If increased glucose metabolism is a product of bioenergetic demand, then we must target the metabolites and signaling proteins, such as HIF- $1 \alpha$, which are critical to cancer cell adaptation to energetic stress. Activation of the protein kinases Akt and mTORC1 is strongly linked to increased glycolytic metabolism, as described in a review (Robey \& Hay 2009). A recently described mechanism that may contribute to Akt regulation of glycolysis is the regulation of mTORC1 signaling pathway by the forkhead box subclass O (FOXO) transcription factors (Chen et al. 2010, Khatri et al. 2010). In this model, oncogene-induced Akt would inactivate the FOXO transcription factors, activating mTORC1-stimualted glycolysis due to decreased function of the tuberous sclerosis complex 1 (TSC1)-TSC2 tumor suppressor complex.
In the scenario where glycolytic metabolism contributes to biosynthetic pathways, a different set of chemotherapeutic targets emerges - those metabolic modifiers that reroute glucose-derived carbon toward biosynthetic pathways, such as TIGAR or PKM2. Association of glycolysis with cell cycle progression, perhaps coordinated by circadian clock proteins, indicates a third avenue to regulate glycolytic metabolism. Although increased glucose metabolism is commonplace in cancer, we predict that glycolysis is enlisted for different purposes in distinct tumors. Effective targeting of the glycolytic program in cancer will therefore require investigation of the contributions of glucose metabolism across the spectrum of cancer.

\section{Glutaminolysis: the 'other' Warburg effect?}

'In conclusion we may mention a remarkable connection, the significance of which is not yet clear, which exists between the glycolytic action of the cell and its action on nitrogen-containing substances. If sections of Flexner rat-carcinoma are placed in sugar-free Ringer's solution at bodytemperature, considerable quantities of ammonia develop.' (Warburg et al. 1931).

If glucose metabolism can be successfully targeted in cancer, will limiting glycolysis be sufficient to eliminate the bioenergetic and biosynthetic underpinnings for transformed cell growth? Unfortunately, some oncogenic events can activate metabolic pathways that can substitute for some or all of the effects of glucose metabolism. One example is the metabolic program induced by oncogenic expression of the Myc transcription factor. Myc is a potent oncogene that is well known for its ability to drive cell cycle progression coupled with increased glycolytic metabolism (Dang et al. 2006). Increased glucose metabolism driven by Myc might suggest glucosedependent cancer cell growth and survival, similar to previous observations of glucose-dependent cell survival driven by Akt (Gottlob et al. 2001, Plas et al. 2001). However, Myc-expressing cells are hypersensitive to limited oxygen availability, rather than glucose metabolism (Brunelle et al. 2004, Yuneva et al. 2007). Dependence on oxidative metabolism in Myctransformed cells may be due to increased glutamine metabolism (Yuneva et al. 2007).

Myc has been shown to directly regulate the transcription of glutamine transporters (Wise et al. 2008), 
but indirect effects on glutaminolysis have also been described. Myc promotes increased expression of glutaminase, an enzyme that converts glutamine to glutamate, by repressing the expression of miRNA-23a/b (Gao et al. 2009). In addition, Myc enhances the overall capacity of the cell to conduct oxidative metabolism by activating the transcription of genes required for increased mitochondrial biogenesis (Li et al. 2005).

Increased expression of enzymes mediating increased glutamine metabolism has been correlated with cell transformation (Knox et al. 1969). Glutamine contributes to biosynthesis by direct incorporation into nascent polypeptides, by supporting NADPH pools, or as a precursor for de novo pyrimidine synthesis (Fig. 4). Glutamine also contributes to cellular bioenergetics by entering the TCA cycle after conversion first to glutamate then to $\alpha$-ketoglutarate. However, decreases in ATP and NAD:NADH ratios were not detected in glutamine-deprived cells (Yuneva et al. 2007). Global metabolic analysis of glutamine-consuming glioblastoma cells suggested that glutamine metabolism provided significant contributions to cellular levels of NADPH and glutamine-derived carbon contributed to phospholipid synthesis (DeBerardinis et al. 2007, Wise et al. 2008). By-products of glutamine consumption are excess quantities of lactate, alanine, and ammonia - the latter reminiscent of Warburg's observation of ammonia production in carcinoma samples.

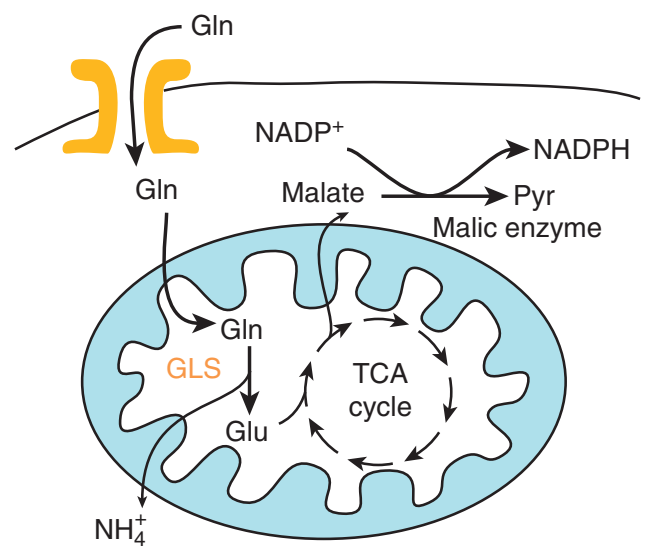

Figure 4 Glutamine metabolism in transformed cells. c-Myc induces the expression of glutamine transporters at the plasma membrane and acts indirectly through miR23 to increase the expression of glutaminase (GLS). Glutamine contributes to several biosynthetic pathways, including the production of NADPH through malic enzyme catalysis of malate exported from the mitochondria.

\section{Combining glutaminolysis and glycolysis}

Similar to the Akt pathway, Myc has the ability to activate glycolysis. However, Myc does not sensitize cells to glucose-limiting conditions, while cells with activated Akt are hypersensitive to interruptions in glycolysis. Increased glutaminolysis can explain the resistance of Myc-expressing cells to glucose-limiting conditions, but it is interesting to consider the reverse situation: why do Akt-expressing cells fail to acquire another sustaining bioenergetic program, such as glutaminolysis or autophagy (Lum et al. 2005), under glucose-limiting conditions? Direct comparison of the metabolic pathways induced by Myc and Akt provides a possible explanation: Akt cells are less prepared for the switch to oxidative forms of metabolism due to insufficient mitochondrial biogenesis (Fan et al. 2010).

The unveiling of Myc-induced glutaminolysis in conjunction with glucose metabolism provides a cautionary note for the targeting of glucose metabolism in cancer therapy. The studies of Myc-induced metabolism demonstrate that increased glucose metabolism does not necessarily render cells hypersensitive to interruptions in glucose metabolism. Although we and others have suggested otherwise in the past (Plas \& Thomas 2009), the observation of increased glucose metabolism by fluorodeoxyglucose positron emission tomography (FDG-PET) or other approaches is not sufficient to suggest chemotherapeutic targeting of glycolytic metabolism. It is necessary to understand and target the complete metabolic effects of oncogenic mutations. The power of this approach was recently demonstrated in glioblastoma cells with activated metabolism of both glucose and glutamine - cell survival was only compromised on inhibition of both glycolysis and glutaminolysis (Yang et al. 2009).

\section{Fatty acid metabolism: metabolism for long-lived cells}

Similar to glucose and glutamine, fatty acid metabolism supports both the biosynthetic and the bioenergetic requirements for cell proliferation and survival. Fatty acids can be converted to triglycerides for storage, phospholipids for membrane biogenesis or oxidized to $\mathrm{CO}_{2}$ for energy production. In proliferating cells, fatty acids are channeled for lipid synthesis, which contributes to membrane production and posttranslational lipid modification of proteins (Bauer et al. 2005). In addition, fatty acid consumption through $\beta$-oxidation can provide a key alternative pathway that can support cancer cell survival when glucose metabolism becomes limiting. The ability to 
efficiently support either biosynthetic or bioenergetic needs may explain an apparent connection between fatty acid metabolism in long-lived cell types, such as memory lymphocytes and cardiac myocytes (Pearce et al. 2009, Chung et al. 2010).

\section{Fatty acid synthesis}

Oncogenic mutations alter the expression and activity of two key enzymes involved in fatty acid synthesis, fatty acid synthase (FASN) and acetyl-CoA carboxylase (ACC; Yoon et al. 2007). Under conditions where glycolysis or glutaminolysis produces excess pyruvate, increased expression of FASN and ACC promotes de novo fatty acid synthesis to maintain the supply of lipids needed for membrane production and protein modifications (Fig. 5). Tumors preferentially use the newly synthesized fatty acids for membrane production rather than utilize dietary fatty acids (Medes et al. 1953, Ookhtens et al. 1984). ACC

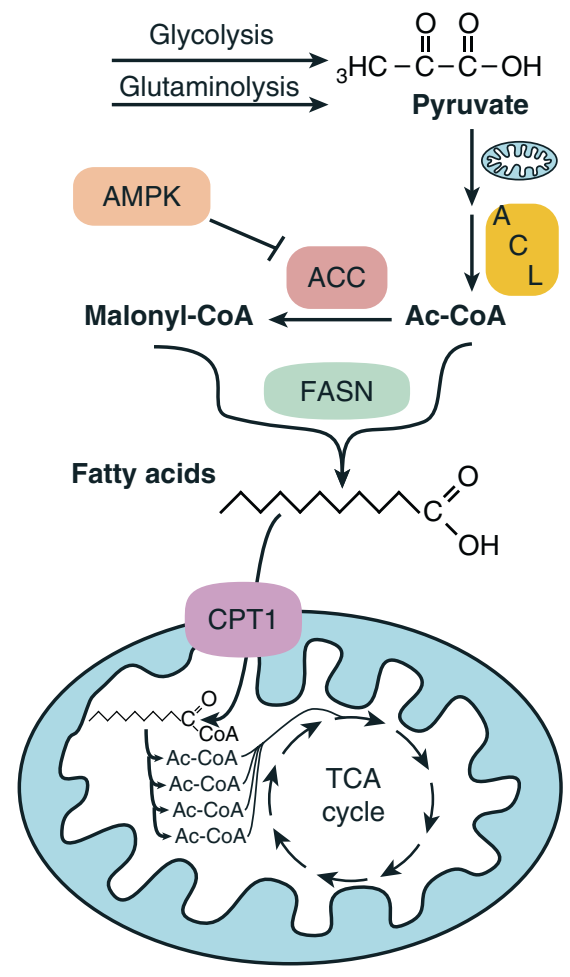

Figure 5 Fatty acid metabolism in transformed cells. Pyruvate derived from upstream metabolic pathways is converted to citrate in the mitochondria then exported to the cytosol, where it fuels ATP citrate lyase (ACL) production of acetyl-CoA. The acetyl-CoA carboxylase (ACC) enzyme produces malonyl-CoA from acetyl-CoA, which together is used in de novo fatty acid synthesis by the fatty acid synthase (FASN) enzyme. Fatty acids can also be catabolized by $\beta$-oxidation. Key steps in this process are the entry of fatty acids into the mitochondria via the CPT1 transporter and inhibition of ACC activity by AMPK. See text for details. produces malonyl-CoA, a key intermediate in fatty acid synthesis that also serves as an allosteric inhibitor of fatty acid oxidation. In some cells, if ACC production of malonyl-CoA drops, fatty acids can be diverted to generate bioenergetic equivalents through mitochondrial $\beta$-oxidation. ACC- and FASN-mediated synthesis of palmitate in breast cancer cells is required to maintain viability (Chajes et al. 2006). Multiple inhibitors of FASN have been developed and show promising effects in vitro and in xenografts (Menendez \& Lupu 2007).

Increased expression of FASN and related enzymes critical for fatty acid synthesis has been noted in multiple types of cancer, including breast, prostate, thyroid, and ovarian cancers (Menendez \& Lupu 2007). FASN expression can be induced by oncogenic activation of the phosphatidylinositol 3-kinase (PI3K) pathway or by the mitogen-activated protein kinase (MAPK) pathway (Van de Sande et al. 2002, Yang et al. 2002). The effects of the PI3K and MAPK pathways are proposed to be mediated through control of the sterol regulatory element-binding protein-1 (SREBP-1) transcription factors, master regulators of fatty acid synthesis (Eberle et al. 2004).

SREBP-1a and SREBP-1c are protein products of the Srebfl gene, differing in their amino termini due to alternative promoter usage. Downstream of Akt, induction of SREBP-1 proteins has been reported to be rapamycin sensitive (Yoon et al. 2007) in HER2 ${ }^{+}$ breast cancer cells, but rapamycin insensitive in glioblastoma cells (Guo et al. 2009). Interestingly, cells expressing elevated SREBP-1 are sensitive to the induction of apoptosis in response to FASN inhibitors in vitro and in xenograft models (Guo et al. 2009). It is not clear why acute inhibition of ongoing fatty acid synthesis induces apoptosis instead of a cytostatic cell cycle arrest. Although activation of SREBP-1 is associated with increased signal transduction, SREBP-1 is also regulated through proteolytic cleavage and by the ubiquitin-proteasome system (Eberle et al. 2004). Thus, significant mechanisms for oncogene regulation of this important transcription factor remain to be investigated.

FASN requires a source for acetyl CoA to mediate increased fatty acid synthesis. In cells with oncogenic activation of PI3K/Akt, acetyl CoA is generated by activation of ATP citrate lyase (ACL; Bauer et al. 2005, Hatzivassiliou et al. 2005). Acting on excess citrate generated under nutrient-rich conditions, ACL converts citrate to acetyl CoA and oxaloacetate. Akt directly phosphorylates and activates ACL catalytic activity (Berwick et al. 2002). Similar to FASN, ACL has emerged as a promising target for disrupting 
oncogene-induced metabolism. ACL knockdown or treatment with pharmacologic inhibitors induced a cytostatic block of cancer cell growth in vitro and in a xenograft model (Hatzivassiliou et al. 2005, Migita et al. 2008).

\section{Fatty acid oxidation}

Cancer cells can shift to oxidation of nonglucose carbon to maintain mitochondrial membrane function and support cell survival. For example, stromal cell interactions can promote a metabolic shift to the oxidation of fatty acids versus glucose to support leukemia (Samudio et al. 2008). Fatty acid oxidation can rescue matrix detachment and promote anchorageindependent survival in an in vitro model of breast cancer (Schafer et al. 2009). Indeed, activating fatty acid oxidation in Akt-transformed cells protects from apoptosis in the absence of glucose (Buzzai et al. 2005).

Fatty acid $\beta$-oxidation is controlled by the carnitine palmitoyl transferase (CPT) system and the availability of cofactors $\mathrm{NAD}^{+}$and $\mathrm{FAD}^{+}$(Eaton et al. 1996). The CPT transport system facilitates the entry of fatty acids into the mitochondria (Fig. 5). CPT-1 is the first and rate-limiting step of fatty acid transport. CPT-1 import of fatty acids into the mitochondria is inhibited by malonyl-CoA, the product of the ACC fatty acid synthesis enzyme, as described above. Activation of AMPK promotes import of fatty acids by phosphorylating and inhibiting ACC, relieving malonyl-CoA repression of CPT-1 (Davies et al. 1990).

In addition to allosteric regulation by malonyl-CoA, CPT-1 fatty acid transport activity is also controlled through transcriptional regulation by upstream signaling pathways. In particular, both growth factors and oncogenic mutations can repress CPTIA transcription by activating the PI3K/Akt pathway (DeBerardinis et al. 2006). Interestingly, re-activation of the dormant fatty acid oxidation pathway via AMPK activation can provide Akt-transformed cells with an alternative energy source that can substitute for glycolysis (Buzzai et al. 2005).

Aggressive cancer cell lines accumulate high levels of free fatty acids, at least partly as a result of increased expression of monoacylglycerol lipase (MAGL; Nomura et al. 2010). Accumulation of fatty acid end products, such as palmitate, contributes to the generation of ROS and ceramide, a proapoptotic second messenger (Obeid et al. 1993). Therefore, cancer cells with increased fatty acid levels require a mechanism to balance lipid synthesis and cytotoxicity. There are two mechanisms that can satisfy this balance of increased fatty acid synthesis, conversion to triglycerides for storage or $\beta$-oxidation for energy production. Upregulation of CPT-1 mRNA in pancreatic $\beta$ cells prevents death induced upon palmitate accumulation (Wan et al. 2010). Inhibition of fatty acid oxidation in human leukemia cells through the loss of CPT-1 by shRNA or treatment with etomoxir sensitized cells to chemotherapy (Samudio et al. 2010). Additionally, MAGL inhibitors suppress the carcinogenic potential of aggressive cancer cells (Nomura et al. 2010).

Of the three metabolic programs that we have considered in this study, fatty acid metabolism holds a number of key advantages for chemotherapeutic targeting. Specificity of FASN inhibitors for cancer cells has been tested extensively with promising results, and the fatty acid oxidation inhibitor etomoxir has been tried in short-term protocols for cardiac disease (Schmidt-Schweda \& Holubarsch 2000, Holubarsch et al. 2007, Menendez \& Lupu 2007). Xenograft tests of efficacy have yielded supportive results. Furthermore, both glycolysis and glutaminolysis appear to mediate their oncogenic effects by contributing to NADPH production and fatty acid synthesis. It is now time to experimentally define the genetic and cell growth parameters that can maximize cytotoxicity elicited by fatty acid metabolism inhibitors, and translate this approach for cancer chemotherapy.

\section{Signaling pathway control of metabolism}

Specific mutations in oncogenes and tumor suppressors are associated with distinct metabolic programs in cancer. Highlighted below are oncogenic mutations that activate metabolic programs in cancer through alterations in signaling pathways.

Akt-induced glycolysis is a common feature in cancer due to the prevalence of activating mutations in PI3K or inactivating mutations in the phosphatase and tensin homolog (PTEN). Both of these mutations increase the abundance of 3,4,5-phosphatidylinositol trisphosphate $\left(\mathrm{PIP}_{3}\right)$, a critical upstream activator of Akt. The requirement for $\mathrm{PIP}_{3}$ in Akt activation can be alleviated by mutations within Akt itself (Carpten et al. 2007). Finally, numerous activating events in upstream tyrosine kinases, such as BCR-ABL, induce Akt signaling and glycolysis by activating PI3K (Boren et al. 2001, Gottschalk et al. 2004). Activated growth factor receptors can also trigger increased fatty acid synthesis through SREBP-1-mediated transcriptional control of FASN (Swinnen et al. 2000, Kumar-Sinha et al. 2003). Owing to its central role in regulating the activation of Akt and glycolysis, PI3K is a major target 
for chemotherapeutic drug development, with several compounds now in clinical trial (Liu et al. 2009).

Downstream of Akt, glycolysis is controlled by evolutionarily conserved substrates: the TSC2 tumor suppressor protein and the FOXO transcription factors (Brugarolas et al. 2003, Khatri et al. 2010). FOXO transcription factors regulate the production of TSC1, a chaperone protein that stabilizes TSC2 (Khatri et al. 2010). TSC2 is a negative regulator of the small GTPase protein known as Rheb, which in turn is critical for activating the protein kinase mTORC1. mTORC1 is a protein kinase complex consisting of the mTOR catalytic subunit in association with Raptor, LST8, and other cofactors. Activated Akt phosphorylates and inhibits the tumor suppressor-like functions of FOXOs and TSC2, activating Rheb and mTORC1. Loss of either FOXO transcription factors, TSC1 or TSC2, is sufficient to activate glycolysis (Khatri et al. 2010). Cancer-associated mutations have been reported in TSC1 and mTORC1 (Knowles et al. 2003, Sato et al. 2010).

Although PI3K/Akt signaling is sufficient to activate glycolysis, tumors can also activate glycolysis via Aktindependent mechanisms. Overexpresion of c-Myc through chromosomal translocation or gene locus amplification leads to direct transcriptional induction of glycolytic enzymes (Osthus et al. 2000). Transcriptional activation of glycolysis through the HIF-1 $\alpha$ transcription factor is also triggered by mutations in the metabolic enzymes SDH and FH (Lehtonen et al. 2004, Sudarshan et al. 2009). p53 inactivation, one of the most common oncogenic mutations, can lead to increased glycolysis by reducing transcription of TIGAR and $\mathrm{SCO}$, which suppress glycolysis (Bensaad et al. 2006, Matoba et al. 2006).

Glutamine catabolism is emerging as an important contributor of NADPH required for nucleotide biosynthesis and carbon for the synthesis of lipids, proteins, and amino acids (DeBerardinis et al. 2007, Wise et al. 2008). The $c$-myc oncogene drives glutamine catabolism in part through suppression of $\mathrm{miR}-23 \mathrm{a} / \mathrm{b}$ enhancing glutaminase expression rendering the cells dependent on glutamine to sustain viability (Gao et al. 2009).

\section{Metabolic programs in chemotherapy}

We have focused on the metabolic programs that are frequently activated in cancer, and how these programs contribute to oncogenesis. As our understanding of the role of metabolism in supporting oncogenesis grows, the key question will be how to exploit cancer cell metabolism to overcome apoptosis resistance and enhance chemotherapeutic responses. Recent approaches aim to interrupt the signaling pathways that lead to oncogenic changes in metabolism, or to directly inhibit the metabolic programs that cancer cells have acquired.

\section{Targeting metabolism}

Direct inhibition of glycolysis has long been considered as a chemotherapeutic strategy in cancer. We previously showed that apoptosis resistance mediated by Akt can be overcome by reducing cellular glycolysis (Plas et al. 2001). A number of compounds directly target the glycolytic pathway, including dichloroacetate (DCA), 2-deoxy-glucose (2-DG), and 3-bromopyruvate (3-Br). DCA is an inhibitor of pyruvate dehydrogenase kinase-1 (PDK-1), a kinase that regulates the flux of pyruvate into mitochondria. By inhibiting PDK-1, DCA redirects pyruvate away from the production of lactate, inducing pyruvate entry into the mitochondrial TCA cycle. DCA can induce increased mitochondrial function and apoptosis in primary glioblastoma cells, and showed therapeutic benefits in a small clinical trial (Bonnet et al. 2007, Michelakis et al. 2010). 2-DG competes with glucose as a substrate for hexokinase preventing glucose phosphorylation and oxidation via glycolysis. In animal models, 2-DG selectively induced cell death in transformed cells when used in combination with other anticancer therapeutics such as paclitaxel or histone deacetylase (HDAC) inhibitors (Maschek et al. 2004, Egler et al. 2008). Similarly, the hexokinase inhibitor 3-Br suppressed xenograft growth of human colorectal carcinoma cells containing activated alleles of Ras or Raf, though it was not clear whether this activity is due to cytotoxic versus cytostatic effects (Yun et al. 2009). Although glycolytic inhibitors demonstrate therapeutic potential in animal models, their application in the clinic is limited at best. A concern regarding glycolysis inhibition is raised by the observation of a selective advantage of colon cancer cells with mutations in K-Ras or B-Raf when glycolysis is inhibited (Yun et al. 2009). This suggests that glycolysis inhibition should be used in combination with other approaches that can prevent the emergence of therapy-resistant cancer cells.

Although direct inhibitors of fatty acid metabolism exhibit specific cytotoxicity for cancer cells in vitro, toxicity and bioavailability issues in vivo have prevented the translation of this approach into the clinic. One of the most attractive targets for inhibition in cancer chemotherapy is FASN, due to the high degree of FASN overexpression in cancer cells. 
A single FASN polypeptide chain contains multiple enzymatic activities, and there is a range of inhibitors that target these enzymatic activities (Menendez \& Lupu 2007). These inhibitors can induce cytotoxic effects in breast cancer cells, especially in combination with other chemotherapeutic agents including paclitaxel (Menendez et al. 2005). Etomoxir, an inhibitor of fatty acid oxidation, can sensitize leukemia and colon cancer cells to apoptosis (Hernlund et al. 2008, Samudio et al. 2010).

\section{Targeting signal transduction}

Therapeutics that target the Akt pathway are also being evaluated in the clinic with mixed results. The most widely used inhibitor is rapamycin, a compound that forms a complex with the cellular protein FKBP12 and inhibits the phosphorylation of substrates by mTORC1 (Abraham \& Gibbons 2007). Rapamycin derivatives were approved by the FDA for various settings in renal cell carcinoma, based on an ability to extend median survival (Hudes et al. 2007, Motzer et al. 2008). Despite the successful application of these drugs, multiple studies have reported cytostatic but not cytotoxic effects of rapamycin and its analogues, resulting in disease stabilization but not regression (Bissler et al. 2008, Motzer et al. 2008, Wolpin et al. 2009). The lack of cytotoxicity may be related to a side effect of inhibition of mTORC1 activation of Akt. Under homeostatic conditions, Akt activation is restrained by an mTORC1-regulated negative feedback loop. Treatment with rapamycin inactivates this restraining mechanism, resulting in increased Akt phosphorylation of multiple substrates (O'Reilly et al. 2006). It is possible that increased Akt signaling confers increased apoptosis resistance, a counterproductive effect in cancer chemotherapy. Dual mTOR/PI3K inhibitors, such as BEZ235, or mTORC1/mTORC2 inhibitors, such as WYE-125132, do not suffer from secondary activation of Akt, and consequently it is possible that these inhibitors will trigger cancer-specific cytotoxicity as opposed to cytostatic effects (Brachmann et al. 2009, Yu et al. 2010).

The antidiabetic compound metformin has significant potential for use in both cancer chemotherapy and cancer prevention, associated with its ability to impede mTORC1 signaling. Cancer cells respond to metformin by activating AMPK (Zhou et al. 2001). We have already described the ability of AMPK to phosphorylate important metabolic regulatory proteins, including p53, CRY1, and ACC. In addition, AMPK impedes mTORC1 signaling through stimulatory phosphorylation of TSC2, and inhibitory phosphorylation of raptor (Inoki et al. 2003, Gwinn et al. 2008). By impairing mTORC1 signaling, AMPK opposes the pathway that signals activation of glycolysis in cancers with upstream activating mutations. AMPK activation in response to metformin may also impair fatty acid synthesis in cancer cells through its effects on ACC and its ability to suppress the expression of SREBP-1 (Zhou et al. 2001). Metformin has been shown to delay or prevent carcinogenesis in diabetic patients (Evans et al. 2005). Incorporation of metformin into chemotherapeutic regimens is under development in multiple clinical trials. It will be important to determine whether metformin efficacy correlates with suppression of glycolysis, fatty acid synthesis, or other alterations in metabolism.

In the above examples, metabolic interventions induced cytotoxic effects, while signaling inhibitors were associated with cytostatic effects. Increasing the specificity of the anti-metabolites or improved targeting of signaling pathways is necessary to achieve cytotoxic responses that can be used in the clinic. Targeting multiple signaling nodes, as exemplified by BEZ235 inactivation of $\mathrm{PI} 3 \mathrm{~K}$ and $\mathrm{mTOR}$, represents one strategy for improving cytotoxic responses. Combining anti-metabolites with pathway-specific therapeutics may also improve chemotherapeutic responses. Maximal cytotoxic responses may be achieved by disrupting the delicate balance between biosynthetic and bioenergetic metabolic pathways in cancer cells.

\section{Conclusions}

Cancer cells derive biosynthetic and bioenergetic benefits from oncogenic mutations that activate glycolysis, glutaminolysis, and fatty acid metabolism. The mechanisms that activate metabolism include signal transduction activation of metabolic genes, induction of metabolism in response to bioenergetic demand, and disruption of temporal control of metabolism. Counteracting metabolic alterations in cancer cells in chemotherapy may be achieved, but potential drawbacks with leading approaches, such as rapamycin or direct glycolysis inhibitors, have been described. This suggests that the differences in the 'metabolic programs' controlled by each oncogene will determine the potential efficacy of targeting metabolism in chemotherapy. As genomic sequencing of cancers finally reveals the full complement of oncogenic mutations driving a particular tumor, we must understand these mutations in terms of the metabolic programs that they control. In this way, metabolic targeting can be used in cooperation with other forms of targeted chemotherapy to improve cancer treatment outcomes. 


\section{Declaration of interest}

The authors declare that there is no conflict of interest that could be perceived as prejudicing the impartiality of the research reported.

\section{Funding}

JF Barger and DR Plas are supported by grant CA133164 from the National Cancer Institute and RSG-08-293-01-CCG from the American Cancer Society.

\section{Acknowledgements}

We thank Dr Ralph DeBerardinis (University of Texas, Southwestern) for critique of the manuscript, and Glenn Doerman for help in preparing the figures.

\section{References}

Abraham RT \& Gibbons JJ 2007 The mammalian target of rapamycin signaling pathway: twists and turns in the road to cancer therapy. Clinical Cancer Research $\mathbf{1 3}$ 3109-3114. (doi:10.1158/1078-0432.CCR-06-2798)

Bauer DE, Hatzivassiliou G, Zhao F, Andreadis C \& Thompson CB 2005 ATP citrate lyase is an important component of cell growth and transformation. Oncogene 24 6314-6322. (doi:10.1038/sj.onc.1208773)

Bensaad K, Tsuruta A, Selak MA, Vidal MN, Nakano K, Bartrons R, Gottlieb E \& Vousden KH 2006 TIGAR, a p53-inducible regulator of glycolysis and apoptosis. Cell 126 107-120. (doi:10.1016/j.cell.2006.05.036)

Bensaad K, Cheung EC \& Vousden KH 2009 Modulation of intracellular ROS levels by TIGAR controls autophagy. EMBO Journal 28 3015-3026. (doi:10.1038/emboj. 2009.242)

Berwick DC, Hers I, Heesom KJ, Moule SK \& Tavare JM 2002 The identification of ATP-citrate lyase as a protein kinase B (Akt) substrate in primary adipocytes. Journal of Biological Chemistry 277 33895-33900. (doi:10.1074/ jbc.M204681200)

Bissler JJ, McCormack FX, Young LR, Elwing JM, Chuck G, Leonard JM, Schmithorst VJ, Laor T, Brody AS, Bean J et al. 2008 Sirolimus for angiomyolipoma in tuberous sclerosis complex or lymphangioleiomyomatosis. New England Journal of Medicine 358 140-151. (doi:10.1056/ NEJMoa063564)

Bonnet S, Archer SL, Allalunis-Turner J, Haromy A, Beaulieu C, Thompson R, Lee CT, Lopaschuk GD, Puttagunta L, Harry G et al. 2007 A mitochondria-K ${ }^{+}$ channel axis is suppressed in cancer and its normalization promotes apoptosis and inhibits cancer growth. Cancer Cell 11 37-51. (doi:10.1016/j.ccr. 2006.10.020)

Boren J, Cascante M, Marin S, Comin-Anduix B, Centelles JJ, Lim S, Bassilian S, Ahmed S, Lee WN \& Boros LG 2001 Gleevec (STI571) influences metabolic enzyme activities and glucose carbon flow toward nucleic acid and fatty acid synthesis in myeloid tumor cells. Journal of Biological Chemistry 276 37747-37753. (doi:10.1074/jbc. M105796200)

Boughattas NA, Levi F, Fournier C, Lemaigre G, Roulon A, Hecquet B, Mathe G \& Reinberg A 1989 Circadian rhythm in toxicities and tissue uptake of 1,2-diamminocyclohexane(trans-1)oxalatoplatinum(II) in mice. Cancer Research 49 3362-3368.

Brachmann SM, Hofmann I, Schnell C, Fritsch C, Wee S, Lane H, Wang S, Garcia-Echeverria C \& Maira SM 2009 Specific apoptosis induction by the dual PI3K/mTor inhibitor NVP-BEZ235 in HER2 amplified and PIK3CA mutant breast cancer cells. PNAS 106 22299-22304. (doi:10.1073/pnas.0905152106)

Brugarolas JB, Vazquez F, Reddy A, Sellers WR \& Kaelin WG Jr 2003 TSC2 regulates VEGF through mTOR-dependent and -independent pathways. Cancer Cell 4 147-158. (doi:10.1016/S1535-6108(03)00187-9)

Bruick RK \& McKnight SL 2001 A conserved family of prolyl-4-hydroxylases that modify HIF. Science 294 1337-1340. (doi:10.1126/science.1066373)

Brunelle JK, Santore MT, Budinger GR, Tang Y, Barrett TA, Zong WX, Kandel E, Keith B, Simon MC, Thompson CB et al. $2004 \mathrm{c}-\mathrm{Myc}$ sensitization to oxygen deprivationinduced cell death is dependent on Bax/Bak, but is independent of p53 and hypoxia-inducible factor-1. Journal of Biological Chemistry 279 4305-4312. (doi:10.1074/jbc.M312241200)

Buzzai M, Bauer DE, Jones RG, Deberardinis RJ, Hatzivassiliou G, Elstrom RL \& Thompson CB 2005 The glucose dependence of Akt-transformed cells can be reversed by pharmacologic activation of fatty acid betaoxidation. Oncogene 24 4165-4173. (doi:10.1038/sj.onc. 1208622)

Carpten JD, Faber AL, Horn C, Donoho GP, Briggs SL, Robbins CM, Hostetter G, Boguslawski S, Moses TY, Savage S et al. 2007 A transforming mutation in the pleckstrin homology domain of AKT1 in cancer. Nature 448 439-444. (doi:10.1038/nature05933)

Chajes V, Cambot M, Moreau K, Lenoir GM \& Joulin V 2006 Acetyl-CoA carboxylase alpha is essential to breast cancer cell survival. Cancer Research 66 5287-5294. (doi:10.1158/0008-5472.CAN-05-1489)

Chen EI, Hewel J, Krueger JS, Tiraby C, Weber MR, Kralli A, Becker K, Yates JR III \& Felding-Habermann B 2007a Adaptation of energy metabolism in breast cancer brain metastases. Cancer Research 67 1472-1486. (doi:10.1158/0008-5472.CAN-06-3137)

Chen Z, Odstrcil EA, Tu BP \& McKnight SL $2007 b$ Restriction of DNA replication to the reductive phase of the metabolic cycle protects genome integrity. Science 316 1916-1919. (doi:10.1126/science.1140958)

Chen CC, Jeon SM, Bhaskar PT, Nogueira V, Sundararajan D, Tonic I, Park Y \& Hay N 2010 FoxOs inhibit mTORC1 and activate akt by inducing the expression of sestrin 3 and rictor. Developmental Cell 18 592-604. (doi:10.1016/ j.devcel.2010.03.008) 
Christofk HR, Vander Heiden MG, Harris MH, Ramanathan A, Gerszten RE, Wei R, Fleming MD, Schreiber SL \& Cantley LC $2008 a$ The M2 splice isoform of pyruvate kinase is important for cancer metabolism and tumour growth. Nature 452 230-233. (doi:10.1038/nature06734)

Christofk HR, Vander Heiden MG, Wu N, Asara JM \& Cantley LC 2008b Pyruvate kinase M2 is a phosphotyrosine-binding protein. Nature 452 181-186. (doi:10.1038/ nature06667)

Chung S, Arrell DK, Faustino RS, Terzic A \& Dzeja PP 2010 Glycolytic network restructuring integral to the energetics of embryonic stem cell cardiac differentiation. Journal of Molecular and Cellular Cardiology 48 725-734. (doi:10.1016/j.yjmcc.2009.12.014)

Clower CV, Chatterjee D, Wang Z, Cantley LC, Vander Heiden MG \& Krainer AR 2010 The alternative splicing repressors hnRNP A1/A2 and PTB influence pyruvate kinase isoform expression and cell metabolism. PNAS 107 1894-1899. (doi:10.1073/pnas. 0914845107)

Dang CV, O’Donnell KA, Zeller KI, Nguyen T, Osthus RC \& Li F 2006 The c-Myc target gene network. Seminars in Cancer Biology 16 253-264. (doi:10.1016/j.semcancer. 2006.07.014)

Dang L, White DW, Gross S, Bennett BD, Bittinger MA, Driggers EM, Fantin VR, Jang HG, Jin S, Keenan MC et al. 2009 Cancer-associated IDH1 mutations produce 2-hydroxyglutarate. Nature 462 739-744. (doi:10.1038/ nature08617)

David CJ, Chen M, Assanah M, Canoll P \& Manley JL 2010 HnRNP proteins controlled by c-Myc deregulate pyruvate kinase mRNA splicing in cancer. Nature 463 364-368. (doi:10.1038/nature08697)

Davies SP, Sim AT \& Hardie DG 1990 Location and function of three sites phosphorylated on rat acetyl-CoA carboxylase by the AMP-activated protein kinase. European Journal of Biochemistry 187 183-190. (doi:10.1111/ j.1432-1033.1990.tb15293.x)

DeBerardinis RJ, Lum JJ \& Thompson CB 2006 Phosphatidylinositol 3-kinase-dependent modulation of carnitine palmitoyltransferase 1A expression regulates lipid metabolism during hematopoietic cell growth. Journal of Biological Chemistry 281 37372-37380. (doi:10.1074/ jbc.M608372200)

DeBerardinis RJ, Mancuso A, Daikhin E, Nissim I, Yudkoff M, Wehrli S \& Thompson CB 2007 Beyond aerobic glycolysis: transformed cells can engage in glutamine metabolism that exceeds the requirement for protein and nucleotide synthesis. PNAS 104 19345-19350. (doi:10.1073/pnas.0709747104)

Eaton S, Bartlett K \& Pourfarzam M 1996 Mammalian mitochondrial beta-oxidation. Biochemical Journal 320 345-357.

Eberle D, Hegarty B, Bossard P, Ferre P \& Foufelle F 2004 SREBP transcription factors: master regulators of lipid homeostasis. Biochimie 86 839-848. (doi:10.1016/ j.biochi.2004.09.018)
Egler V, Korur S, Failly M, Boulay JL, Imber R, Lino MM \& Merlo A 2008 Histone deacetylase inhibition and blockade of the glycolytic pathway synergistically induce glioblastoma cell death. Clinical Cancer Research 14 3132-3140. (doi:10.1158/1078-0432.CCR-07-4182)

Epstein AC, Gleadle JM, McNeill LA, Hewitson KS, O'Rourke J, Mole DR, Mukherji M, Metzen E, Wilson MI, Dhanda A et al. 2001 C. elegans EGL-9 and mammalian homologs define a family of dioxygenases that regulate HIF by prolyl hydroxylation. Cell 107 43-54. (doi:10.1016/S0092-8674(01)00507-4)

Evans JM, Donnelly LA, Emslie-Smith AM, Alessi DR \& Morris AD 2005 Metformin and reduced risk of cancer in diabetic patients. BMJ 330 1304-1305. (doi:10.1136/bmj. 38415.708634.F7)

Fan Y, Dickman KG \& Zong WX 2010 Akt and c-Myc differentially activate cellular metabolic programs and prime cells to bioenergetic inhibition. Journal of Biological Chemistry 285 7324-7333. (doi:10.1074/ jbc.M109.035584)

Fu L, Pelicano H, Liu J, Huang P \& Lee C 2002 The circadian gene Period 2 plays an important role in tumor suppression and DNA damage response in vivo. Cell 111 41-50. (doi:10.1016/S0092-8674(02)00961-3)

Gao P, Tchernyshyov I, Chang TC, Lee YS, Kita K, Ochi T, Zeller KI, De Marzo AM, Van Eyk JE, Mendell JT et al. 2009 c-Myc suppression of miR-23a/b enhances mitochondrial glutaminase expression and glutamine metabolism. Nature 458 762-765. (doi:10.1038/nature07823)

Gery S, Komatsu N, Baldjyan L, Yu A, Koo D \& Koeffler HP 2006 The circadian gene per1 plays an important role in cell growth and DNA damage control in human cancer cells. Molecular Cell 22 375-382. (doi:10.1016/j.molcel. 2006.03.038)

Gery S, Komatsu N, Kawamata N, Miller CW, Desmond J, Virk RK, Marchevsky A, McKenna R, Taguchi H \& Koeffler HP 2007a Epigenetic silencing of the candidate tumor suppressor gene Per1 in non-small cell lung cancer. Clinical Cancer Research 13 1399-1404. (doi:10.1158/ 1078-0432.CCR-06-1730)

Gery S, Virk RK, Chumakov K, Yu A \& Koeffler HP $2007 b$ The clock gene Per2 links the circadian system to the estrogen receptor. Oncogene 26 7916-7920. (doi:10. 1038/sj.onc.1210585)

Gorbacheva VY, Kondratov RV, Zhang R, Cherukuri S, Gudkov AV, Takahashi JS \& Antoch MP 2005 Circadian sensitivity to the chemotherapeutic agent cyclophosphamide depends on the functional status of the CLOCK/BMAL1 transactivation complex. PNAS 102 3407-3412. (doi:10.1073/pnas.0409897102)

Gottlob K, Majewski N, Kennedy S, Kandel E, Robey RB \& Hay N 2001 Inhibition of early apoptotic events by Akt/PKB is dependent on the first committed step of glycolysis and mitochondrial hexokinase. Genes and Development 15 1406-1418. (doi:10.1101/gad.889901)

Gottschalk S, Anderson N, Hainz C, Eckhardt SG \& Serkova NJ 2004 Imatinib (STI571)-mediated changes in 
glucose metabolism in human leukemia BCR-ABL-positive cells. Clinical Cancer Research 10 6661-6668. (doi:10. 1158/1078-0432.CCR-04-0039)

Gross S, Cairns RA, Minden MD, Driggers EM, Bittinger MA, Jang HG, Sasaki M, Jin S, Schenkein DP, Su SM et al. 2010 Cancer-associated metabolite 2-hydroxyglutarate accumulates in acute myelogenous leukemia with isocitrate dehydrogenase 1 and 2 mutations. Journal of Experimental Medicine 207 339-344. (doi:10.1084/jem.20092506)

Guo D, Prins RM, Dang J, Kuga D, Iwanami A, Soto H, Lin KY, Huang TT, Akhavan D, Hock MB et al. 2009 EGFR signaling through an Akt-SREBP-1-dependent, rapamycin-resistant pathway sensitizes glioblastomas to antilipogenic therapy. Science Signaling 2 ra82. (doi:10.1126/scisignal.2000446)

Gwinn DM, Shackelford DB, Egan DF, Mihaylova MM, Mery A, Vasquez DS, Turk BE \& Shaw RJ 2008 AMPK phosphorylation of raptor mediates a metabolic checkpoint. Molecular Cell 30 214-226. (doi:10.1016/j.molcel. 2008.03.003)

Hao HX, Khalimonchuk O, Schraders M, Dephoure N, Bayley JP, Kunst H, Devilee P, Cremers CW, Schiffman JD, Bentz BG et al. 2009 SDH5, a gene required for flavination of succinate dehydrogenase, is mutated in paraganglioma. Science 325 1139-1142. (doi:10.1126/science.1175689)

Hatzivassiliou G, Zhao F, Bauer DE, Andreadis C, Shaw AN, Dhanak D, Hingorani SR, Tuveson DA \& Thompson CB 2005 ATP citrate lyase inhibition can suppress tumor cell growth. Cancer Cell 8 311-321. (doi:10.1016/j.ccr.2005. 09.008)

Haus E, Halberg F, Pauly JE, Cardoso S, Kuhl JF, Sothern RB, Shiotsuka RN \& Hwang DS 1972 Increased tolerance of leukemic mice to arabinosyl cytosine with schedule adjusted to circadian system. Science 177 80-82. (doi:10.1126/science.177.4043.80)

He X, Ee PL, Coon JS \& Beck WT 2004 Alternative splicing of the multidrug resistance protein 1/ATP binding cassette transporter subfamily gene in ovarian cancer creates functional splice variants and is associated with increased expression of the splicing factors PTB and SRp20. Clinical Cancer Research 10 4652-4660. (doi:10.1158/ 1078-0432.CCR-03-0439)

Hernlund E, Ihrlund LS, Khan O, Ates YO, Linder S, Panaretakis T \& Shoshan MC 2008 Potentiation of chemotherapeutic drugs by energy metabolism inhibitors 2-deoxyglucose and etomoxir. International Journal of Cancer 123 476-483. (doi:10.1002/ijc.23525)

Holubarsch CJ, Rohrbach M, Karrasch M, Boehm E, Polonski L, Ponikowski P \& Rhein S 2007 A double-blind randomized multicentre clinical trial to evaluate the efficacy and safety of two doses of etomoxir in comparison with placebo in patients with moderate congestive heart failure: the ERGO (etomoxir for the recovery of glucose oxidation) study. Clinical Science 113 205-212. (doi:10.1042/CS20060307)

Hudes G, Carducci M, Tomczak P, Dutcher J, Figlin R, Kapoor A, Staroslawska E, Sosman J, McDermott D,
Bodrogi I et al. 2007 Temsirolimus, interferon alfa, or both for advanced renal-cell carcinoma. New England Journal of Medicine 356 2271-2281. (doi:10.1056/ NEJMoa066838)

Hwang PM, Bunz F, Yu J, Rago C, Chan TA, Murphy MP, Kelso GF, Smith RA, Kinzler KW \& Vogelstein B 2001 Ferredoxin reductase affects p53-dependent, 5-fluorouracil-induced apoptosis in colorectal cancer cells. Nature Medicine 7 1111-1117. (doi:10.1038/ nm1001-1111)

Inoki K, Zhu T \& Guan KL 2003 TSC2 mediates cellular energy response to control cell growth and survival. Cell 115 577-590. (doi:10.1016/S0092-8674(03)00929-2)

Ivan M, Haberberger T, Gervasi DC, Michelson KS, Gunzler V, Kondo K, Yang H, Sorokina I, Conaway RC, Conaway JW et al. 2002 Biochemical purification and pharmacological inhibition of a mammalian prolyl hydroxylase acting on hypoxia-inducible factor. PNAS 99 13459-13464. (doi:10.1073/pnas.192342099)

Jin W, McCutcheon IE, Fuller GN, Huang ES \& Cote GJ 2000 Fibroblast growth factor receptor-1 alpha-exon exclusion and polypyrimidine tract-binding protein in glioblastoma multiforme tumors. Cancer Research $\mathbf{6 0}$ 1221-1224.

Jones RG, Plas DR, Kubek S, Buzzai M, Mu J, Xu Y, Birnbaum MJ \& Thompson CB 2005 AMP-activated protein kinase induces a p53-dependent metabolic checkpoint. Molecular Cell 18 283-293. (doi:10.1016/ j.molcel.2005.03.027)

Khatri S, Yepiskoposyan H, Gallo CA, Tandon P \& Plas DR 2010 FOXO3a regulates glycolysis via transcriptional control of tumor suppressor TSC1. Journal of Biological Chemistry 285 15960-15965. (doi:10.1074/jbc.M110. 121871)

Kitevska T, Spencer DM \& Hawkins CJ 2009 Caspase-2: controversial killer or checkpoint controller? Apoptosis 14 829-848. (doi:10.1007/s10495-009-0365-3)

Knowles MA, Habuchi T, Kennedy W \& Cuthbert-Heavens D 2003 Mutation spectrum of the 9q34 tuberous sclerosis gene TSC1 in transitional cell carcinoma of the bladder. Cancer Research 63 7652-7656.

Knox WE, Horowitz ML \& Friedell GH 1969 The proportionality of glutaminase content to growth rate and morphology of rat neoplasms. Cancer Research 29 669-680.

Kuhajda FP 2000 Fatty-acid synthase and human cancer: new perspectives on its role in tumor biology. Nutrition 16 202-208. (doi:10.1016/S0899-9007(99)00266-X)

Kuhajda FP, Piantadosi S \& Pasternack GR 1989 Haptoglobin-related protein (Hpr) epitopes in breast cancer as a predictor of recurrence of the disease. New England Journal of Medicine 321 636-641. (doi:10.1056/ NEJM198909073211003)

Kumar-Sinha C, Ignatoski KW, Lippman ME, Ethier SP \& Chinnaiyan AM 2003 Transcriptome analysis of HER2 reveals a molecular connection to fatty acid synthesis. Cancer Research 63 132-139. 
Lamia KA, Storch KF \& Weitz CJ 2008 Physiological significance of a peripheral tissue circadian clock. PNAS 105 15172-15177. (doi:10.1073/pnas.0806717105)

Lamia KA, Sachdeva UM, DiTacchio L, Williams EC, Alvarez JG, Egan DF, Vasquez DS, Juguilon H, Panda S, Shaw RJ et al. 2009 AMPK regulates the circadian clock by cryptochrome phosphorylation and degradation. Science 326 437-440. (doi:10.1126/ science.1172156)

Lehtonen R, Kiuru M, Vanharanta S, Sjoberg J, Aaltonen LM, Aittomaki K, Arola J, Butzow R, Eng C, HusgafvelPursiainen K et al. 2004 Biallelic inactivation of fumarate hydratase $(\mathrm{FH})$ occurs in nonsyndromic uterine leiomyomas but is rare in other tumors. American Journal of Pathology 164 17-22.

Li F, Wang Y, Zeller KI, Potter JJ, Wonsey DR, O’Donnell KA, Kim JW, Yustein JT, Lee LA \& Dang CV 2005 Myc stimulates nuclearly encoded mitochondrial genes and mitochondrial biogenesis. Molecular and Cellular Biology 25 6225-6234. (doi:10.1128/MCB.25.14. 6225-6234.2005)

Liu P, Cheng H, Roberts TM \& Zhao JJ 2009 Targeting the phosphoinositide 3-kinase pathway in cancer. Nature Reviews. Drug Discovery 8 627-644. (doi:10.1038/ nrd2926)

Lum JJ, Bauer DE, Kong M, Harris MH, Li C, Lindsten T \& Thompson CB 2005 Growth factor regulation of autophagy and cell survival in the absence of apoptosis. Cell 120 237-248. (doi:10.1016/j.cell.2004.11.046)

Marcucci G, Maharry K, Wu YZ, Radmacher MD, Mrozek K, Margeson D, Holland KB, Whitman SP, Becker H, Schwind S et al. 2010 IDH1 and IDH2 gene mutations identify novel molecular subsets within de novo cytogenetically normal acute myeloid leukemia: a Cancer and Leukemia Group B Study. Journal of Clinical Oncology 28 2348-2355. (doi:10.1200/JCO.2009.27.3730)

Mardis ER, Ding L, Dooling DJ, Larson DE, McLellan MD, Chen K, Koboldt DC, Fulton RS, Delehaunty KD, McGrath SD et al. 2009 Recurring mutations found by sequencing an acute myeloid leukemia genome. New England Journal of Medicine 361 1058-1066. (doi:10.1056/NEJMoa0903840)

Maschek G, Savaraj N, Priebe W, Braunschweiger P, Hamilton K, Tidmarsh GF, De Young LR \& Lampidis TJ 2004 2-deoxy-D-glucose increases the efficacy of adriamycin and paclitaxel in human osteosarcoma and non-small cell lung cancers in vivo. Cancer Research 64 31-34. (doi:10.1158/0008-5472.CAN-03-3294)

Matoba S, Kang JG, Patino WD, Wragg A, Boehm M, Gavrilova O, Hurley PJ, Bunz F \& Hwang PM 2006 p53 regulates mitochondrial respiration. Science $\mathbf{3 1 2}$ 1650-1653. (doi:10.1126/science.1126863)

Mazurek S, Boschek CB, Hugo F \& Eigenbrodt E 2005 Pyruvate kinase type M2 and its role in tumor growth and spreading. Seminars in Cancer Biology 15 300-308. (doi:10.1016/j.semcancer.2005.04.009)
Medes G, Thomas A \& Weinhouse S 1953 Metabolism of neoplastic tissue. IV. A study of lipid synthesis in neoplastic tissue slices in vitro. Cancer Research 13 27-29.

Menendez JA \& Lupu R 2007 Fatty acid synthase and the lipogenic phenotype in cancer pathogenesis. Nature Reviews. Cancer 7 763-777. (doi:10.1038/nrc2222)

Menendez JA, Vellon L, Colomer R \& Lupu R 2005 Pharmacological and small interference RNA-mediated inhibition of breast cancer-associated fatty acid synthase (oncogenic antigen-519) synergistically enhances Taxol (paclitaxel)-induced cytotoxicity. International Journal of Cancer 115 19-35. (doi:10.1002/ijc.20754)

Michelakis ED, Sutendra G, Dromparis P, Webster L, Haromy A, Niven E, Maguire C, Gammer TL, Mackey JR, Fulton D et al. 2010 Metabolic modulation of glioblastoma with dichloroacetate. Science Translational Medicine 2 31ra34. (doi:10.1126/scitranslmed.3000677)

Migita T, Narita T, Nomura K, Miyagi E, Inazuka F, Matsuura M, Ushijima M, Mashima T, Seimiya H, Satoh Y et al. 2008 ATP citrate lyase: activation and therapeutic implications in non-small cell lung cancer. Cancer Research 68 8547-8554. (doi:10.1158/0008-5472.CAN08-1235)

Motzer RJ, Escudier B, Oudard S, Hutson TE, Porta C, Bracarda S, Grunwald V, Thompson JA, Figlin RA, Hollaender N et al. 2008 Efficacy of everolimus in advanced renal cell carcinoma: a double-blind, randomised, placebo-controlled phase III trial. Lancet 372 449-456. (doi:10.1016/S0140-6736(08)61039-9)

Nomura DK, Long JZ, Niessen S, Hoover HS, Ng SW \& Cravatt BF 2010 Monoacylglycerol lipase regulates a fatty acid network that promotes cancer pathogenesis. Cell 140 49-61. (doi:10.1016/j.cell.2009.11.027)

Nutt LK, Margolis SS, Jensen M, Herman CE, Dunphy WG, Rathmell JC \& Kornbluth S 2005 Metabolic regulation of oocyte cell death through the CaMKII-mediated phosphorylation of caspase-2. Cell 123 89-103. (doi:10.1016/ j.cell.2005.07.032)

Nutt LK, Buchakjian MR, Gan E, Darbandi R, Yoon SY, Wu JQ, Miyamoto YJ, Gibbons JA, Andersen JL, Freel CD et al. 2009 Metabolic control of oocyte apoptosis mediated by 14-3-3zeta-regulated dephosphorylation of caspase-2. Developmental Cell 16 856-866. (doi:10.1016/ j.devcel.2009.04.005)

Obeid LM, Linardic CM, Karolak LA \& Hannun YA 1993 Programmed cell death induced by ceramide. Science 259 1769-1771. (doi:10.1126/science.8456305)

Ookhtens M, Kannan R, Lyon I \& Baker N 1984 Liver and adipose tissue contributions to newly formed fatty acids in an ascites tumor. American Journal of Physiology 247 R146-R153.

O'Reilly KE, Rojo F, She QB, Solit D, Mills GB, Smith D, Lane H, Hofmann F, Hicklin DJ, Ludwig DL et al. 2006 mTOR inhibition induces upstream receptor tyrosine kinase signaling and activates Akt. Cancer Research 66 1500-1508. (doi:10.1158/0008-5472.CAN-05-2925) 
Osthus RC, Shim H, Kim S, Li Q, Reddy R, Mukherjee M, Xu Y, Wonsey D, Lee LA \& Dang CV 2000 Deregulation of glucose transporter 1 and glycolytic gene expression by c-Myc. Journal of Biological Chemistry 275

21797-21800. (doi:10.1074/jbc.C000023200)

Ozturk N, Lee JH, Gaddameedhi S \& Sancar A 2009 Loss of cryptochrome reduces cancer risk in p53 mutant mice. PNAS 106 2841-2846. (doi:10.1073/pnas.0813028106)

Parsons DW, Jones S, Zhang X, Lin JC, Leary RJ, Angenendt P, Mankoo P, Carter H, Siu IM, Gallia GL et al. 2008 An integrated genomic analysis of human glioblastoma multiforme. Science 321 1807-1812. (doi:10.1126/ science.1164382)

Pearce EL, Walsh MC, Cejas PJ, Harms GM, Shen H, Wang LS, Jones RG \& Choi Y 2009 Enhancing CD8 T-cell memory by modulating fatty acid metabolism. Nature 460 103-107. (doi:10.1038/nature08097)

Plas DR \& Thomas G 2009 Tubers and tumors: rapamycin therapy for benign and malignant tumors. Current Opinion in Cell Biology 21 230-236. (doi:10.1016/j.ceb. 2008.12.013)

Plas DR, Talapatra S, Edinger AL, Rathmell JC \& Thompson CB 2001 Akt and Bcl-xL promote growth factorindependent survival through distinct effects on mitochondrial physiology. Journal of Biological Chemistry 276 12041-12048. (doi:10.1074/jbc.M010551200)

Pollard PJ, Briere JJ, Alam NA, Barwell J, Barclay E, Wortham NC, Hunt T, Mitchell M, Olpin S, Moat SJ et al. 2005 Accumulation of Krebs cycle intermediates and over-expression of HIF1alpha in tumours which result from germline FH and SDH mutations. Human Molecular Genetics 14 2231-2239. (doi:10.1093/hmg/ddi227)

Robey RB \& Hay N 2009 Is Akt the "Warburg kinase"? Akt-energy metabolism interactions and oncogenesis Seminars in Cancer Biology 19 25-31. (doi:10.1016/ j.semcancer.2008.11.010)

Sahar S \& Sassone-Corsi P 2009 Metabolism and cancer: the circadian clock connection. Nature Reviews. Cancer 9 886-896. (doi:10.1038/nrc2747)

Samudio I, Fiegl M, McQueen T, Clise-Dwyer K \& Andreeff M 2008 The Warburg effect in leukemia-stroma cocultures is mediated by mitochondrial uncoupling associated with uncoupling protein 2 activation. Cancer Research 68 5198-5205. (doi:10.1158/00085472.CAN-08-0555)

Samudio I, Harmancey R, Fiegl M, Kantarjian H, Konopleva M, Korchin B, Kaluarachchi K, Bornmann W, Duvvuri S, Taegtmeyer $\mathrm{H}$ et al. 2010 Pharmacologic inhibition of fatty acid oxidation sensitizes human leukemia cells to apoptosis induction. Journal of Clinical Investigation 120 142-156. (doi:10.1172/JCI38942)

Sato T, Nakashima A, Guo L, Coffman K \& Tamanoi F 2010 Single amino-acid changes that confer constitutive activation of mTOR are discovered in human cancer. Oncogene 29 2746-2752. (doi:10.1038/onc.2010.28)

Schafer ZT, Grassian AR, Song L, Jiang Z, Gerhart-Hines Z, Irie HY, Gao S, Puigserver P \& Brugge JS 2009
Antioxidant and oncogene rescue of metabolic defects caused by loss of matrix attachment. Nature 461 109-113. (doi:10.1038/nature08268)

Schernhammer ES, Kroenke CH, Laden F \& Hankinson SE 2006 Night work and risk of breast cancer. Epidemiology 17 108-111. (doi:10.1097/01.ede.0000190539.03500.c1)

Schmidt-Schweda S \& Holubarsch C 2000 First clinical trial with etomoxir in patients with chronic congestive heart failure. Clinical Science 99 27-35. (doi:10.1042/ CS19990235)

Selak MA, Armour SM, MacKenzie ED, Boulahbel H, Watson DG, Mansfield KD, Pan Y, Simon MC, Thompson CB \& Gottlieb E 2005 Succinate links TCA cycle dysfunction to oncogenesis by inhibiting HIF-alpha prolyl hydroxylase. Cancer Cell 7 77-85. (doi:10.1016/ j.ccr.2004.11.022)

Shurbaji MS, Kalbfleisch JH \& Thurmond TS 1996 Immunohistochemical detection of a fatty acid synthase (OA-519) as a predictor of progression of prostate cancer. Human Pathology 27 917-921. (doi:10.1016/S00468177(96)90218-X)

Sidi S, Sanda T, Kennedy RD, Hagen AT, Jette CA, Hoffmans R, Pascual J, Imamura S, Kishi S, Amatruda JF et al. 2008 Chk1 suppresses a caspase-2 apoptotic response to DNA damage that bypasses p53, Bcl-2, and caspase-3. Cell 133 864-877. (doi:10.1016/j.cell. 2008.03.037)

Sudarshan S, Sourbier C, Kong HS, Block K, Valera Romero VA, Yang Y, Galindo C, Mollapour M, Scroggins B, Goode N et al. 2009 Fumarate hydratase deficiency in renal cancer induces glycolytic addiction and hypoxiainducible transcription factor 1alpha stabilization by glucose-dependent generation of reactive oxygen species. Molecular and Cellular Biology 29 4080-4090. (doi:10.1128/MCB.00483-09)

Swinnen JV, Heemers H, Deboel L, Foufelle F, Heyns W \& Verhoeven G 2000 Stimulation of tumor-associated fatty acid synthase expression by growth factor activation of the sterol regulatory element-binding protein pathway. Oncogene 19 5173-5181. (doi:10.1038/sj.onc.1203889)

Takahashi JS, Hong HK, Ko CH \& McDearmon EL 2008 The genetics of mammalian circadian order and disorder: implications for physiology and disease. Nature Reviews. Genetics 9 764-775. (doi:10.1038/nrg2430)

Toyokuni S, Okamoto K, Yodoi J \& Hiai H 1995 Persistent oxidative stress in cancer. FEBS Letters 358 1-3. (doi:10.1016/0014-5793(94)01368-B)

Tu BP, Kudlicki A, Rowicka M \& McKnight SL 2005 Logic of the yeast metabolic cycle: temporal compartmentalization of cellular processes. Science 310 1152-1158. (doi:10.1126/science.1120499)

Van de Sande T, De Schrijver E, Heyns W, Verhoeven G \& Swinnen JV 2002 Role of the phosphatidylinositol 3'-kinase/PTEN/Akt kinase pathway in the overexpression of fatty acid synthase in LNCaP prostate cancer cells. Cancer Research 62 642-646. 
Vaughn AE \& Deshmukh M 2008 Glucose metabolism inhibits apoptosis in neurons and cancer cells by redox inactivation of cytochrome $c$. Nature Cell Biology 10 1477-1483. (doi:10.1038/ncb1807)

Wallace DC 2005 A mitochondrial paradigm of metabolic and degenerative diseases, aging, and cancer: a dawn for evolutionary medicine. Annual Review of Genetics 39 359-407. (doi:10.1146/annurev.genet.39.110304.095751)

Wan J, Jiang L, Lu Q, Ke L, Li X \& Tong N 2010 Activation of PPARdelta up-regulates fatty acid oxidation and energy uncoupling genes of mitochondria and reduces palmitate-induced apoptosis in pancreatic beta-cells. Biochemical and Biophysical Research Communications 391 1567-1572. (doi:10.1016/j.bbrc.2009.12.127)

Wang GL, Jiang BH, Rue EA \& Semenza GL 1995 Hypoxia-inducible factor 1 is a basic-helix-loop-helix-PAS heterodimer regulated by cellular $\mathrm{O} 2$ tension. PNAS 92 5510-5514. (doi:10.1073/pnas.92.12.5510)

Wang C, Norton JT, Ghosh S, Kim J, Fushimi K, Wu JY, Stack MS \& Huang S 2008 Polypyrimidine tract-binding protein (PTB) differentially affects malignancy in a cell line-dependent manner. Journal of Biological Chemistry 283 20277-20287. (doi:10.1074/jbc.M803682200)

Warburg O, Posener K \& Negelein E 1931 VIII. The metabolism of the carcinoma cell. In The Metabolism of Tumours, pp 129-169. Ed O Warburg. New York: Richard R. Smith, Inc.

Ward PS, Patel J, Wise DR, Abdel-Wahab O, Bennett BD, Coller HA, Cross JR, Fantin VR, Hedvat CV, Perl AE et al. 2010 The common feature of leukemia-associated IDH1 and IDH2 mutations is a neomorphic enzyme activity converting alpha-ketoglutarate to 2-hydroxyglutarate. Cancer Cell 17 225-234. (doi:10. 1016/j.ccr.2010.01.020)

Wise DR, DeBerardinis RJ, Mancuso A, Sayed N, Zhang XY, Pfeiffer HK, Nissim I, Daikhin E, Yudkoff M, McMahon SB et al. 2008 Myc regulates a transcriptional program that stimulates mitochondrial glutaminolysis and leads to glutamine addiction. PNAS 105 18782-18787. (doi:10. 1073/pnas.0810199105)

Wolpin BM, Hezel AF, Abrams T, Blaszkowsky LS, Meyerhardt JA, Chan JA, Enzinger PC, Allen B, Clark JW, Ryan DP et al. 2009 Oral mTOR inhibitor everolimus in patients with gemcitabine-refractory metastatic pancreatic cancer. Journal of Clinical Oncology 27 193-198. (doi:10. 1200/JCO.2008.18.9514)
Yang YA, Han WF, Morin PJ, Chrest FJ \& Pizer ES 2002 Activation of fatty acid synthesis during neoplastic transformation: role of mitogen-activated protein kinase and phosphatidylinositol 3-kinase.

Experimental Cell Research 279 80-90. (doi:10.1006/ excr.2002.5600)

Yang C, Sudderth J, Dang T, Bachoo RM, McDonald JG \& DeBerardinis RJ 2009 Glioblastoma cells require glutamate dehydrogenase to survive impairments of glucose metabolism or Akt signaling. Cancer Research 69 7986-7993. (doi:10.1158/0008-5472. CAN-09-2266)

Yoon S, Lee MY, Park SW, Moon JS, Koh YK, Ahn YH, Park BW \& Kim KS 2007 Up-regulation of acetyl-CoA carboxylase alpha and fatty acid synthase by human epidermal growth factor receptor 2 at the translational level in breast cancer cells. Journal of Biological Chemistry 282 26122-26131. (doi:10.1074/jbc. M702854200)

Yu K, Shi C, Toral-Barza L, Lucas J, Shor B, Kim JE, Zhang WG, Mahoney R, Gaydos C, Tardio L et al. 2010 Beyond rapalog therapy: preclinical pharmacology and antitumor activity of WYE-125132, an ATP-competitive and specific inhibitor of mTORC1 and mTORC2.

Cancer Research 70 621-631. (doi:10.1158/0008-5472. CAN-09-2340)

Yun J, Rago C, Cheong I, Pagliarini R, Angenendt P, Rajagopalan H, Schmidt K, Willson JK, Markowitz S, Zhou S et al. 2009 Glucose deprivation contributes to the development of KRAS pathway mutations in tumor cells. Science 325 1555-1559. (doi:10.1126/science.1174229)

Yuneva M, Zamboni N, Oefner P, Sachidanandam R \& Lazebnik Y 2007 Deficiency in glutamine but not glucose induces MYC-dependent apoptosis in human cells. Journal of Cell Biology 178 93-105. (doi:10.1083/jcb. 200703099)

Zhao S, Lin Y, Xu W, Jiang W, Zha Z, Wang P, Yu W, Li Z, Gong L, Peng Y et al. 2009 Glioma-derived mutations in IDH1 dominantly inhibit IDH1 catalytic activity and induce HIF-1alpha. Science 324 261-265. (doi:10.1126/ science.1170944)

Zhou G, Myers R, Li Y, Chen Y, Shen X, Fenyk-Melody J, Wu M, Ventre J, Doebber T, Fujii N et al. 2001 Role of AMP-activated protein kinase in mechanism of metformin action. Journal of Clinical Investigation 108 1167-1174. (doi:10.1172/JCI13505) 